\title{
Epidemic trends, public health response and health system capacity: the Chilean experience in four months of the COVID-19 pandemic
}

\author{
Mauricio Canals ${ }^{1}$, Cristóbal Cuadrado ${ }^{1}$, Andrea Canals ${ }^{1}$, Karla Yohannessen ${ }^{1}$, Luis A. Lefio ${ }^{1}$, \\ Maria P. Bertoglia' , Pamela Eguiguren ${ }^{1}$, Izkia Siches², Verónica Iglesias', Oscar Arteaga ${ }^{1}$
}

Suggested citation Canals M, Cuadrado C, Canals A, Yohannessen K, Lefio LA, Bertoglia MP, et al. Epidemic trends, public health response and health system capacity: the Chilean experience in four months of the COVID-19 pandemic. Rev Panam Salud Publica. 2020;44:e99. https://doi.org/10.26633/RPSP.2020.99

ABSTRACT

Objectives. To report the surveillance of COVID-19 pandemic in Chile and analyse the response to public health interventions implemented from 3 March to 30 June 2020 and to assess the risks of collapse of the health care system.

Methods. We analysed the effective reproductive number, underreporting of cases, burden of critical beds, case fatality ratio and number of diagnostic RT-PCR for SARS-CoV-2.

Results. After an accelerated onset, the COVID-19 pandemic seemed to be relatively controlled in Chile (late April 2020), with reproductive numbers close to 1.00. However, at this time, the load of infected patients was high, with an important number of underreported cases; the diagnostic effort was still limited and heterogeneous across regions. After 1 May up to 30 June a marked exponential increase in the number of cases was observed with a peak on June 14. In this last period the occupation of intensive care unit beds increased to saturation level (89\% nationally; 95\% in the Metropolitan Region).

Conclusions. Our findings suggest that the implemented public health interventions have been initially effective in decreasing the spread of the pandemic. Premature decisions to relax these interventions may have resulted in a rebound in cases with a rapid saturation of the health care system.

Keywords $\quad$ Coronavirus infections; pandemics; public health; health policy; health systems; Chile.

In Chile, the first case of COVID-19 was confirmed on 3 March, almost two months after the novel coronavirus SARSCoV-2 was officially declared by China CDC as the causal agent of the outbreak initiated on Wuhan on 17 November 2019 (1).

The responses of countries to the pandemic range over a diversity of strategies (2-5) and the current evidence on those strategies still relies mostly on modelling studies based on developing knowledge and available public data (6). From the experience of countries with large-scale community transmission such as China, Italy or Spain, it has been learned that COVID-19 requires unprecedented mobilization of health systems (7). The demand on health care systems, especially intensive care units (ICU), coming from large numbers of people becoming ill simultaneously has stressed the health systems.

The threat from COVID-19 is dependent on the number of new cases occurring simultaneously in a given time and the capacity of a country's health care system to respond to the increasing demand for health care (7). According to the World Health Organization, a comprehensive national response should include public health measures that break chains of person-to-person transmission (identification, isolation, testing, and clinical care for all cases; tracing and quarantine of all contacts), as well as other public health and social measures involving all sectors to suppress or stop community spread of

Universidad de Chile, Santiago, Chile. $\bowtie$ Mauricio Canals, mcanals@uchile.cl

Hospital San Juan de Dios, Santiago, Chile 
COVID-19 (actions by individuals, institutions, communities, local and national governments) (8). The prompt decisionmaking at the national level regarding public health actions and the involvement of all sectors in order to ensure that every sector takes ownership of and participates in the response are key to success (9). Moreover, the capacity for the health care system to effectively respond to the demand will depend on the available resources, particularly hospital beds, intensive care units (ICU) capacity and specialized human resources.

In Chile, during the four month-period after the first case was officially reported, several public health measures have been undertaken to both attempt to stop the spread of COVID-19 and to strengthen the health care system response capacity.

The objective of this study is to report the surveillance of COVID-19 pandemic and to analyse the response to public health interventions implemented during the first 120 days of the pandemic, from 3 March to 30 June 2020.

\section{MATERIAL AND METHODS}

We conducted an observational ecological study based on official daily public reports from the Ministry of Health of Chile, including new confirmed cases, severe cases requiring admission to ICU, deaths attributable to COVID-19, and the number of new diagnostic test (RT-PCR) for SARS-CoV-2 detection both at the national and subnational levels (regions) (10).

To monitor the evolving situation of the pandemic five main indicators were used: 1 ) estimates of the effective reproductive number $R_{e} ; 2$ ) estimates of the underreporting of cases; 3) estimates of the burden of ICU beds occupation; 4) estimates of the corrected (delay-adjusted) case fatality ratio; and 5) number of diagnostic RT-PCR for SARS-CoV-2 performed.

We calculated $\operatorname{Re}(t)$ using the method developed by Cori et al. (11). We considered the last 2 weeks (14 days) and a serial interval $\tau=5$ days (10) with usual variability between 3 and 7 days (12-14).

Underreporting of cases was estimated according to the method proposed by Russell et al. $(15,16)$. The crude fatality ratio (quotient between the number of deaths and the number of total cases at time $t$ ) was corrected for the lag between diagnosis and death, on average about 13 days; however, the lag period can be shorter or longer than average, which is determined by the probability distribution of dying at a given time after diagnosis. An adapted version of the R code provided by Russell et al. $(15,16)$ was used to estimate the corrected case-fatality ratio $(L c)$. According to the same authors the underreport correction was estimated from the difference between the corrected fatality ratio and a reference value that was $1.38 \%$ (16).

We estimated the burden of critical beds based on the index proposed by González et al. (17), which we modified to: $I_{\text {ICU }}=\frac{I C U r}{0.5 I C U}$, where ICU is the reported number of ICUs in Chile (18) and ICUr is the daily number of occupied critical beds reported by the Ministry of Health. $I_{I C U}>1$ means that there is an overload. This number of beds includes both public and private hospital providers.

Since April 9, the Ministry of Health is reporting the number of diagnostic test (RT-PCR) performed for each country region. These data not always correspond to the exact number of samples per region since exams are sent for analysis elsewhere when their number exceeds the region's PCR testing capacity. In spite of this limitation, we consider the available data useful as the best proxy for the diagnostic effort at subnational level.

The diagnostic effort for each region was estimated as the ratio between the average daily PCR between 7 and 20 May (last 14 days), divided by the total population of the region. Thus, this value represents the average daily amount of PCR per 100,000 inhabitants in the region (PCR rate per 100,000 inhabitants). We also calculated the average number of new cases per day per region, for the same period $\left(C^{*}\right)$. The ratio between these values, $D c=C^{*} /(P C R$ rate $)$, indicates the daily average increase of new COVID-19 cases for each point of increase in diagnostic effort rate (per 1,000,000 inhabitants). In addition, we calculated the number of PCR tests per confirmed case, for the whole country and each region.

Since our study is based on secondary data from the Chilean Ministry of Health's official daily public reports it did not required approval from an Ethics Committee.

\section{RESULTS}

\section{Case characteristics}

As of 30 June, a total of 261,215 cases had been reported with a cumulative incidence of 1608.7 cases per 100,000 inhabitants, distributed similarly among males and females (man/woman ratio $=1,074)$. The average age of confirmed cases was 41.72 years ( \pm 18.15 standard deviation), with a median of 40 years. Patients admitted into ICU totalled 2016, with an age $60.4 \pm 16.8$ years ( $\mathrm{Me}=61.9$ years). The deceased totalled 5,688 cases, with an age of $73.3 \pm 14.5$ years and $(\mathrm{Me}=74.8$ years $)$.

\section{Epidemiological surveillance}

In Chile, the COVID-19 pandemic began on 3 March with the detection of the first imported case. From that moment on, it presented a rapid exponential increase. The main public health interventions were case isolation and contact tracing, jointly implemented with successive social distancing interventions such as closure of schools and universities country-wide (15 March), national overnight curfew (22 March), lockdown of communes (municipalities) in Santiago Metropolitan Region (26 March), Temuco (Araucanía Region, 28 March), Chillán (Ñuble Region, 28 March), Osorno (Los Lagos Region, 30 March) and Arica y Parinacota Region (16 April). Considering the important increase in the number of cases from 2 May, a total of 30 municipalities were forced into lockdown on May 8 and later included the entire capital city of Santiago (May 15). The epidemic curve of confirmed new cases presented a deceleration on day 25 of the pandemic (27 March). Subsequently, there was an increase at a lower rate and stabilization at around 400 confirmed cases per day from 9 April to 1 May. A marked increase in the epidemic curve was evident since 2 May, with a rapid increase particularly due to a growing outbreak on poor and densely populated areas of Santiago, with a peak on midJune (Figure 1).

However, based on the case fatality adjusted for delay, a significant underreport of new cases was estimated (Figure 2). We estimated that nearly 50\% (CI 95\%: 43\% - 56\%) of the symptomatic cases would have been detected at 30 June, day 120 of the outbreak, with an important decline starting in early April, 


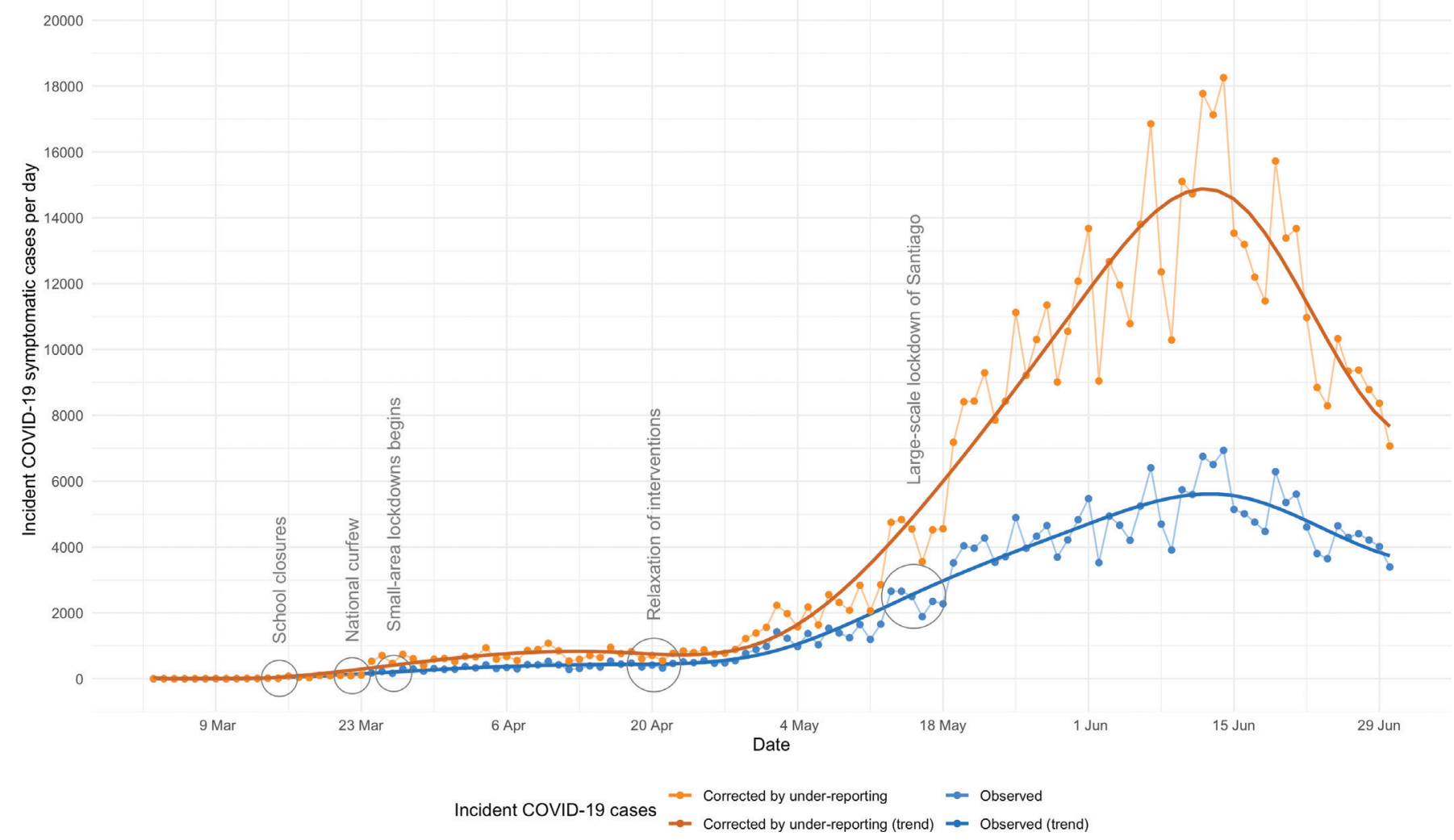

Incident COVID-19 confirmed cases (PCR+) reported by the national authority per day are ploted on blue dots. Incident COVID-19 symptomatic cases corrected by under-reporting per day are ploted on orange dots. Solid dark lines represent the smoothed trend for each curve.

Source: The authors based on data from the Ministry of Health of Chile.

suggesting that the testing capacity of the country reached its roof at that point and was not able to expand at the rate of the epidemic spread.

The reproductive number $\left(R_{e}(t)\right)$ progressively decreased, stabilising at values close to 1.0 between 13 and 27 April, with a significant increase after this date, stabilizing around 1.3 to 1.4 at the end of May, but decreasing to values lower than 1.0 from 20 June to the last day covered in our study (30 June) (Figure 3).

Despite the initial decrease in the speed of the spread of COVID-19 in the country, eight regions had acceleration with respect to the previous week, and nine regions had a reproductive number higher than one (Table 1).

Up to 30 June, a total of 1,120,177 PCR tests have been performed for COVID-19, with a rate of 3.97 tests per confirmed case. The diagnostic effort is highly variable between regions. In the Metropolitan region for each point of increase in PCR rate the number of daily cases increases significantly (Table 2).

The burden on critical beds in the first 50 days of the pandemic remained at values that were tolerable at the country level, but with a heterogeneous distribution at the regional level. However, after the rapid increment of cases, at 30 June the situation had reached very critical levels with high demand and occupation of ICU beds, almost doubling the pre-pandemic capacity of ICU beds (1,200 ICU beds; 6.2 beds / 100,000 inhabitant).

When comparing the trajectory of the Chilean epidemic with initially modelled scenarios, after an accelerated starting period the epidemic trajectory evolved according to a more favourable scenario, but with a critical increase since the first days of May. Likewise, the occupation of ICU beds, which was initially above the expected values but below saturation threshold, by the end of May the demand of critical beds reached 1,000 ICU occupied and 2,497 by the end of June $\left(\mathrm{I}_{\mathrm{ICU}}=1.49\right)$.

\section{DISCUSSION}

COVID-19 has become a pandemic compromising many countries and leading to dramatic scenarios, such as in Italy, Spain and the United States. However, some countries, including South Korea, China, Japan, Taiwan and Hong Kong, have achieved relative control of the pandemic, probably associated with the surveillance response and early public health interventions based on their previous experience with SARS in 2002-2003 (19). China opted for an early lockdown with severe restrictions on domestic and international travel, disinfection of buildings and extensive testing, associated with a large increase in the health system capacity $(2,20)$. South Korea implemented an active strategy of free and massive screening for symptomatic people, case contacts and travellers; schools were closed, remote work was recommended, and large gatherings were prohibited (21). The use of masks, disinfectants and thermal detection in buildings were widespread. There have been no blockages or restrictions on movement, and people under quarantine were monitored by the government and the police through smartphone apps, with offenders punished. Private 
FIGURE 2. Case fatality ratio and underreporting estimates for COVID-19 in Chile, April-June 2020. A) Crude and corrected case fatality ratio. B) Under-reporting estimates, with $95 \%$ confidence intervals
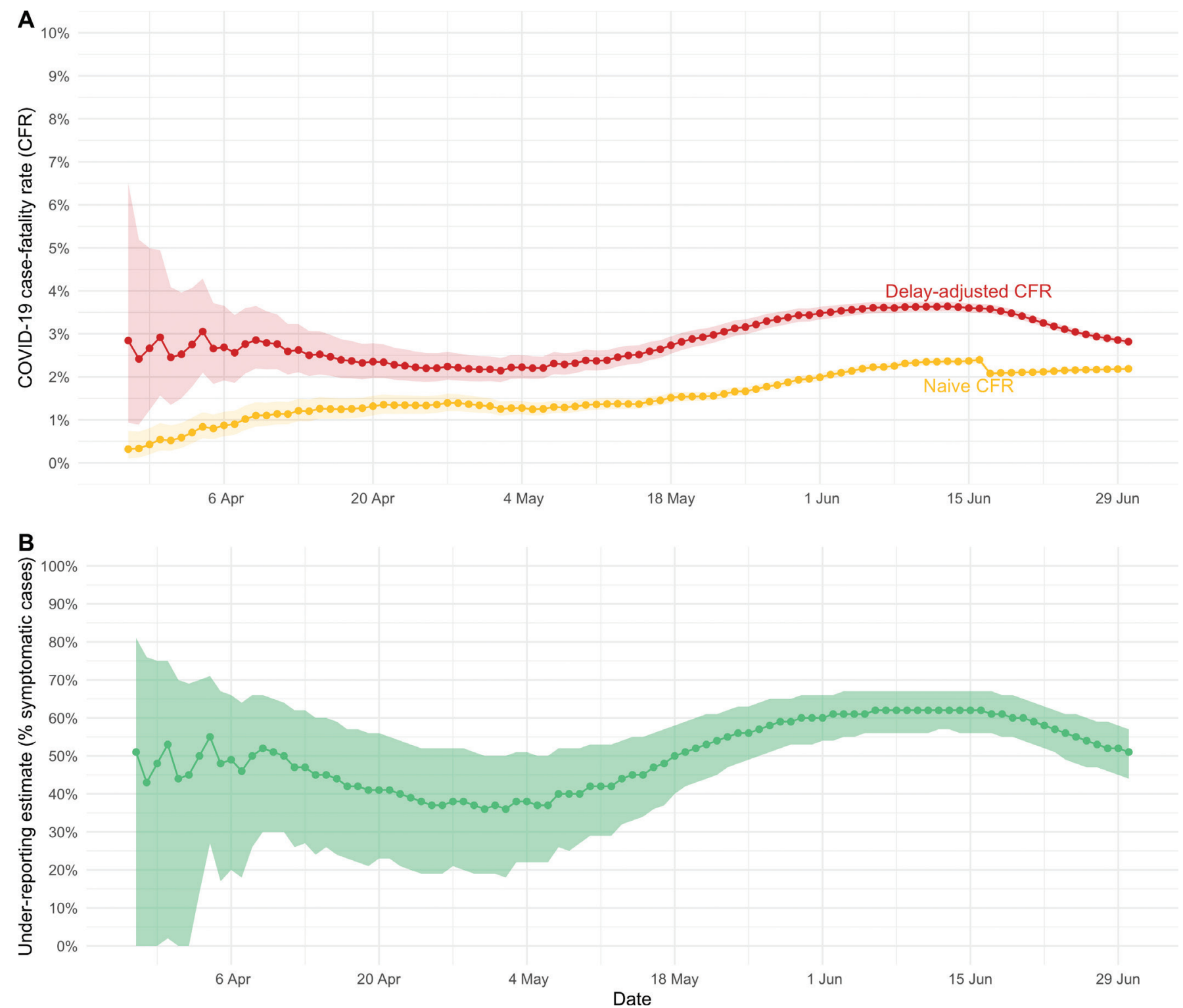

A) Naive (red) and delay-adjusted (yellow) case fatality rate per day. Break in the naive CFR in June 16 is explained by the inclusion of 31.422 cases not previously reported. B) Estimates of proportion of the expected symptomatic cases that are underreported (green). Dots represent mean estimates; shaded areas $95 \%$ confidence intervals. Source: The authors based on data from the Ministry of Health of Chile.

sector companies were actively involved in the dissemination and collection of virus-related information, including data on confirmed COVID-19 patients, along with nationality, gender and age of the patients, places visited by patients, and close contact tracing (21). In Hong Kong, Singapore and Japan, surveillance systems were used to identify potential cases and their contacts, diagnostic tests were developed from the outset, and laboratory testing capacity was increased (22). Different strategies were used to control travellers entering these locations, from partial entry restrictions to mandatory 14-day quarantine of non-local visitors. Taiwan worked actively on the case identification and authorities tracked down infected people and mapped cases while residents' 14-day travel history was integrated with their health insurance card details; educating the public about the risks and precautions associated with COVID19 has also been important (2).

A key issue for epidemiologists is to help policy makers decide the main goals of mitigation, for example, minimizing associated morbidity and mortality, avoiding an epidemic peak that saturates health care services, keeping the effects on the economy within manageable levels, and flattening the epidemic curve gaining time for the discovery of therapeutic drugs or a vaccine. Epidemiological interventions should be aimed at: a) preventing susceptible population from viral exposure, with policies to reduce human mobility, increase social distancing or incentivize individual hygienic measures (23); b) identifying exposed contacts and prevent recurrent exposure from infected patients with case and contact management 
FIGURE 3. Evolution of the reproductive number for COVID-19 epidemic in Chile, March-June 2020

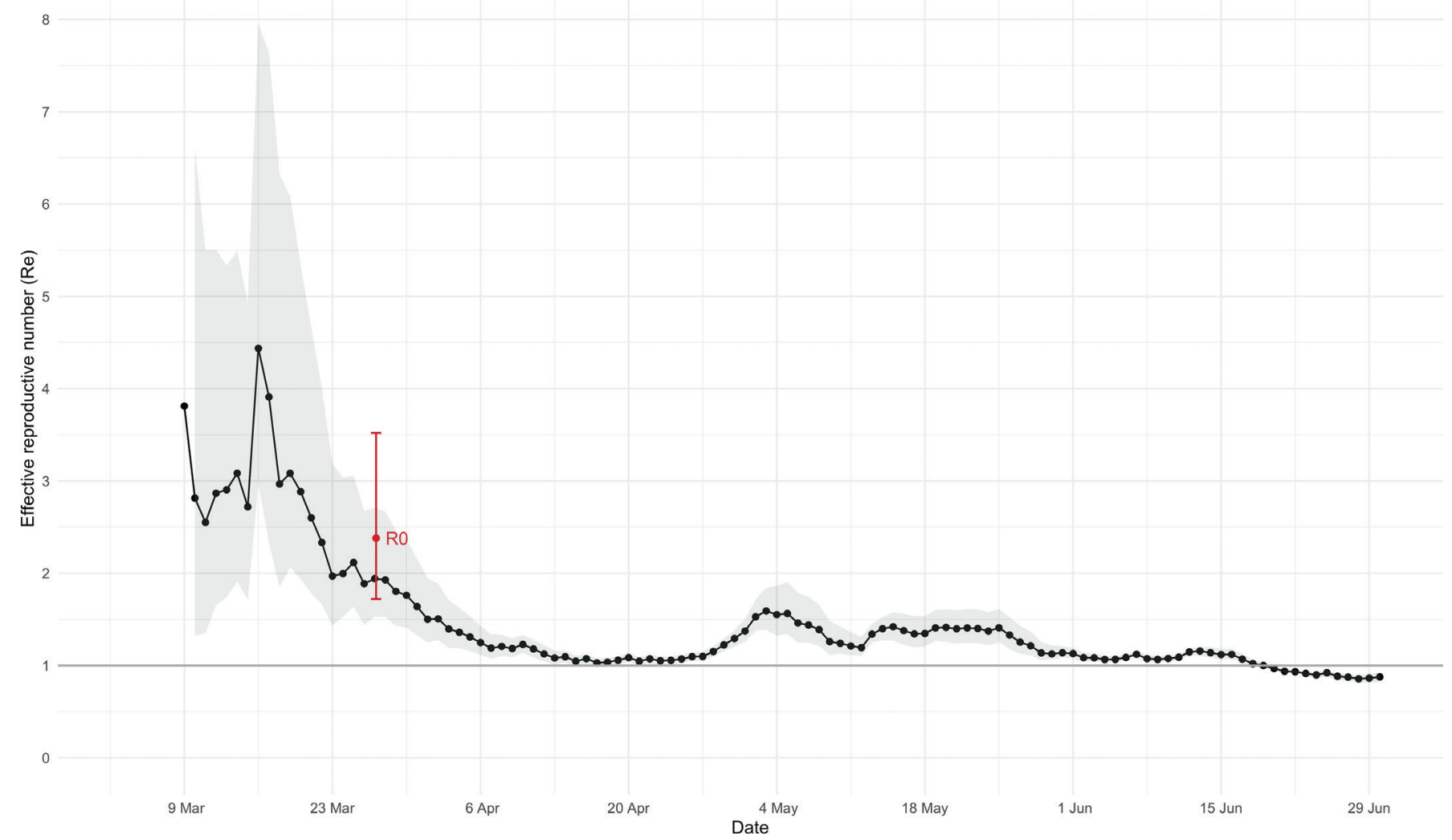

Mean estimates of the effective reproductive number (Re) over time is ploted on black dots, $95 \%$ confidence intervals are represented by the grey area. Basic reproductive number (R0) with $95 \%$ confidence internal presented in red. Source: The authors based on data from the Ministry of Health of Chile.

TABLE 1. Estimation of the basic and effective reproductive number of COVID-19, regions of Chile, 2020

\begin{tabular}{|c|c|c|c|c|}
\hline Region & $\mathrm{R}_{0}$ & (Crl 0.95) & $\mathrm{R}_{\mathrm{e}} 30 /$ June & (Crl 0.95) \\
\hline Arica y Parina & 1,57 & $(1,22-2,53)$ & 1,13 & $(1,00-1,26)$ \\
\hline Tarapacá & 1,34 & $(1,12-1,93)$ & 0,90 & $(0,82-0,99)$ \\
\hline Antofagasta & 1,39 & $(1,11-2,17)$ & 1,02 & $(0,97-1,07)$ \\
\hline Atacama & 1,09 & $(0,97-1,37)$ & 1,28 & $(1,12-1,44)$ \\
\hline Coquimbo & 1,18 & $(0,96-1,72)$ & 1,07 & $(0,99-1,17)$ \\
\hline Valparaíso & 1,62 & $(1,31-2,55)$ & 0,94 & $(0,90-0,99)$ \\
\hline Metropolitana & 2,09 & $(1,73-3,28)$ & 0,81 & $(0,76-0,87)$ \\
\hline O'Higgins & 0,99 & $(0,82-1,38)$ & 0,98 & $(0,93-1,03)$ \\
\hline Maule & 1,21 & $(0,99-1,77)$ & 0,93 & $(0,87-1,00)$ \\
\hline Ñuble & 1,66 & $(1,28-2,74)$ & 0,86 & $(0,73-1,00)$ \\
\hline Biobío & 1,95 & $(1,59-3,10)$ & 0,98 & $(0,93-1,04)$ \\
\hline Araucanía & 1,87 & $(1,53-2,94)$ & 0,96 & $(0,83-1,10)$ \\
\hline Los Ríos & 1,70 & $(1,41-2,60)$ & 1,05 & $(0,86-1,31)$ \\
\hline Los Lagos & 1,62 & $(1,30-2,55)$ & 0,93 & $(0,79-1,06)$ \\
\hline Aysén & 1,11 & $(0,99-1,42)$ & 1,79 & $(0,98-3,07)$ \\
\hline Magallanes & 1,86 & $(1,47-3,05)$ & 1,04 & $(0,84-1,26)$ \\
\hline Chile & 2,36 & $(1,95-3,76)$ & 0,87 & $(0,82-0,91)$ \\
\hline
\end{tabular}

$\mathrm{R}_{0}$, basic reproductive number, based on the first three weeks of the epidemic (3-24 March 2020); $\mathrm{R}_{\mathrm{e}}$, effective reproductive number, based on last two weeks of the epidemic (16-30 June 2020).

(test-trace-isolate) and; c) actions to identify carriers of the virus, trough passive and active screening strategies (23). Among these measures, isolating symptomatic individuals and tracing and quarantining their contacts are the most essential ones to
TABLE 2. Average number of new cases $\left(C^{*}\right)$, PCR rate per 10,000 inhabitants and ratio of detected cases by PCR unity (Dc), 11-30 June 2020, Regions of Chile

\begin{tabular}{lrrr}
\multicolumn{1}{c}{ Region } & $C^{*}$ 11-30 June & $P C R$ rate $($ per 100.000 inhab. $)$ & Dc \\
Arica y Parinacota & 39,9 & 68,5 & 0,6 \\
Tarapacá & 94,9 & 105,4 & 0,9 \\
Antofagasta & 274,4 & 94,4 & 2,9 \\
Atacama & 39,5 & 88,1 & 0,4 \\
Coquimbo & 81,4 & 41,0 & 2,0 \\
Valparaíso & 268,2 & 43,7 & 6,1 \\
Metropolitana & 2852,5 & 111,6 & 25,6 \\
O'Higgins & 246,3 & 45,1 & 5,5 \\
Maule & 166,5 & 66,7 & 2,5 \\
Ñuble & 34,6 & 52,9 & 0,7 \\
Biobío & 202,1 & 95,8 & 2,1 \\
Araucanía & 30,8 & 45,8 & 0,7 \\
Los Ríos & 10,8 & 58,7 & 0,2 \\
Los Lagos & 31,1 & 104,8 & 0,3 \\
Aysén & 1,1 & 69,1 & 0,0 \\
Magallanes & 12,6 & 90,7 & 0,1 \\
Chile & 4386,8 & 85,9 & 51,1 \\
\hline
\end{tabular}

stop the transmission chain (24). It has been proposed that in a disease with an $R_{0}=2.5$, at least $70 \%$ of the contacts should be traced at the beginning of the epidemic in order to control an outbreak (23). 
In the four month analysed period, based on the public health interventions implemented in Chile, we identified four phases in the country's response to the early epidemic: first phase, between 13 and 15 March; second phase, between 16 and 26 March; third phase, between 26 March and 1 May; and fourth after 1 May.

During the first phase, the effort was focused on the detection and traceability of imported cases and on educating the population on hygiene and social distancing measures. The number of total cases reached 75 on 15 March. The following day (16 March), the government decreed the closure of schools, and universities voluntarily suspended face-to-face activities. At this time the initial estimates of $R_{e}(t)$ were high; however, with very few and sporadic cases, it was not possible yet to estimate a categorical value of the basic reproductive number $\left(R_{0}\right)$ since the best estimate of it is obtained by reaching the breakdown of the epidemic curve associated with control and/or mitigation measures (25).

The second stage (16 to $26 \mathrm{March}$ ) began with the closure of schools and universities. In this stage a state of national catastrophe was decreed (19 March) which allowed the government to impose a partial lockdown of Santiago Metropolitan Region (quarantine for small-areas within the city, called "dynamic quarantines") and a national overnight curfew (10 pm to $5 \mathrm{am}$ ). Several measures were taken, including restrictions for public gatherings, quarantine of older adults, 14 days-quarantine for travellers coming from countries with high COVID-19 incidence, quarantine of contacts of COVID-19 cases, restrictions for international traveling (air, land or water transport) and some domestic travels. A clear break in the epidemic curve was observed on 27 March (24 days after the first case of COVID19), making possible to estimate the basic reproductive number: $R_{0}=2.38$ (95\% CI: 1.72-3.52). Beyond the known limitations of ecological studies (26) and specifically of the complexities in the calculation of the basic reproduction number (27), the apparent break in the viral transmission, however, cannot be associated to the dynamic quarantines since this strategy only started one day prior to the break of the epidemic curve.

The third phase (26 March to 1 May) began with the lockdown of the cities of Temuco, Chillán and Osorno which followed the small-area lockdowns of Santiago Metropolitan Region. At this stage it could be observed a progressive decrease in $R_{e}(t)$ values to close to 1.0 similar to the experience of other countries (28). In this phase, a series of dynamic quarantines were established or lifted according to the number of new cases, the speed of spread of the disease, the density of cases $/ \mathrm{km}^{2}$, and the age profile and social vulnerability of the involved population. The compliance with quarantines was verified, controlling the entry and exit of quarantined areas in sanitary cords. In general terms, a relative but fragile stabilization was achieved in the number of daily cases in ranges that allow an adequate response from the health care system, with case fatality rates converging to those estimates reported in the international literature $(15,5)$. Early evidence suggests that this small-area lockdowns were effective in reducing human mobility and the effective reproductive number at this stage (29). Although the effective reproductive number was 1.06, the number of actively infectious individuals was close to 5,000 which could generate a maximal of 5,300 new cases in a serial period (5 days) with the subsequently increasing load for the health care system gradually.

The fourth phase (after 1 May) was characterized by a marked exponential increase in the number of cases with a quantity of active infected that has risen 8.9 times between the 1 May and 14 June (from 7,756 to 69,134). A key feature of this period was the delayed response from the authorities to implement larger-scale lockdowns after the rapid spread of cases in the poorest neighborhoods of Santiago, with high rates of household overcrowding and poverty. An increase in the occupation of ICU followed, currently being 89\% nationally (95\% in the Metropolitan Region) with 2,044 COVID patients undergoing invasive mechanical ventilation (30) and a significant elevation in the number of deaths, reaching 5,688 by 30 June. Later in this phase large-scale lockdowns were implemented in Santiago, that included at least five million people in the Metropolitan Region, with a recent decrease in the reproductive number, the daily cases, the load of active infected individuals and the percent of positive tests $(24.2 \%)$.

Some considerations make the analysis more complex. First, there is a clear underreporting of cases that can be estimated to be close to $50 \%$ at the end of the analysed period. This questions the real value of $R e$ and the effectiveness of case tracing efforts and contacts isolation. The relationship between the number of reported cases and PCR rate is still high (51.1) in average, indicating that for each point of increase in the number of PCR rate per 100,000 inhabitants, a total of 235 cases are expected to be added each week. Second, when comparing the number of PCR tests per confirmed case, the ratio observed in Chile (3.97) is much lower than the ones reported in countries such as Vietnam (671.9) or Taiwan (134.7), but close to those informed in some Latin American countries such as Argentina (12.1) and Peru (9.5) (31). A lower ratio of PCR test per confirmed case suggest that the diagnostic efforts are insufficient. Moreover, there are important differences in the diagnostic efforts made across regions of the country. Even when PCR exams are reported according to the region where the laboratory that performed the exam is located and not according to provenance of samples, this heterogeneity across regions could suggest important differences in terms of the capacity to early identify and isolate cases.

The effective reproductive number was decreasing progressively to values close to 1.0, but after 1 May there was an important increase in its value stabilizing between 1.3 and 1.4 on mid-May but decreasing recently to values lower than one from mid-June. The estimation of $\mathrm{R} e$ is sensitive to both the method used and the serial interval. We accounted for this by using serial interval values between 3 and 7 , based on the usual extreme values reported in the literature, to estimate the credibility intervals of the $R_{e}(t)(13,32,33)$.

In order to analyse and monitor the epidemic of COVID-19, we first considered three thresholds of ICU beds occupation: 500 ICU beds, approximately $50 \%$ of the initial availability, and $2,000 \mathrm{ICU}$ as an estimate of the maximum possible capacity. On 30 June, the Chilean government informed 2,075 ICU beds occupied, which is close to saturation level. The burden of ICU bed occupancy is well represented by the load index that is 1.49 at that date.

In conclusion, the COVID-19 pandemic in Chile showed a first phase of accelerated onset, followed by partially successful initial contention efforts that led to a full epidemic growth after first measures where relaxed and a delayed response to reinstall mitigation interventions occurred. The epidemic had a great increase in mid-June and in the last days is decreasing, but with high number of daily cases. Although our study is ecological and caution is needed when analysing the results, our findings 
suggest that the public health interventions implemented at an early stage, including school and university closures and the progressive implementation of city quarantines may have been effective for a time in decreasing the spread of the disease. However, when the pandemic was relatively controlled, three challenges may have constituted short-term risks for the country that unfolded in a failure to adequately manage the outbreak: i) the load of actively infected diagnosed patients was high with important numbers of underreported cases; ii) a diagnostic effort that was limited and heterogeneous across regions; ii) a limited reserve of ICU beds. In this context, political decisions leading to de-escalate public health interventions may have triggered an accelerated rebound in cases with a rapid high stress, near saturation level, of the health care system. The Chilean experience shows how apparently well-resourced and prepared countries could find difficulties in the management of the pandemic, suffering large outbreaks in the context of highly unequal urban areas such as Santiago.

Authors' contributions. All authors contributed to the study design, the analysis of the results, the discussion and the manuscript writing; $\mathrm{MC}, \mathrm{CC}$ and $\mathrm{AC}$ contributed to the statistical analysis.

Conflicts of interests. None declared.

\section{Funding. Funded by ANID-COVID 0960.}

Disclaimer. Authors hold sole responsibility for the views expressed in the manuscript, which may not necessarily reflect the opinion or policy of the RPSP/PAJPH or the Pan American Health Organization (PAHO).

\section{REFERENCES}

1. Mizumoto K, Kagaya K, Chowell G. (2020). Transmissibility of 2019 Novel Coronavirus: zoonotic vs. human to human transmission, China, 2019-2020. medRxiv preprint doi: https://doi.org/10.1101/2 020.03.16.20037036.

2. Wang J and Wang Z. Strengths, Weaknesses, Opportunities and Threats (SWOT) Analysis of China's Prevention and Control Strategy for the COVID-19 Epidemic. Int J Environ Res Public Health. 2020; doi:10.3390/ijerph17072235. https://www.mdpi. com $/ 1660-4601 / 17 / 7 / 2235$

3. Salazar Mather T, Gallo Marin B, Medina Perez G, Christophers B, Paiva ML, Oliva $\mathrm{R}$ et al. Love in the time of COVID-19: negligence in the Nicaraguan response. Lancet Glob Health. 2020; https://doi. org/10.1016/S2214109X(20)301315. https://www.thelancet.com/ pdfs/journals/langlo/PIIS2214-109X(20)30131-5.pdf

4. Sebastiani G, Massa M, Riboli E.. Covid-19 epidemic in Italy: evolution, projections and impact of government measures. Eur J Epidemiol. 2020; https://doi.org/10.1007/s10654-020-00631-6.

5. Peña S, Cuadrado C, Rivera-Aguirre A, Hasdell R, Nazif-Munoz J, Yusuf $\mathrm{M}$ et al. PoliMap: A taxonomy proposal for mapping and understanding the global policy response to COVID-19. Polimap COVID-19; 2020. https://polimap.org/.

6. Nussbaumer-Streit B, Mayr V, Dobrescu AI, Chapman A, Persad E, Klerings I, et al. Quarantine alone or in combination with other public health measures to control COVID-19: a rapid review. Cochrane Database Syst Rev. 2020; https:/ /www.cochranelibrary. com/cdsr/doi/10.1002/14651858.CD013574/full.

7. WHO-Europe. Strengthening the health system response to COVID-19. Recommendations for the WHO European Region. Policy brief (1 April 2020). http://www.euro.who.int/_data/assets/ pdf_file/0003/436350/strengthening-health-system-responseCOVID-19.pdf?ua $=1$.

8. WHO. Overview of Public Health and Social Measures in the context of COVID-19; 2020. https://www.who.int/publications/i/item/ overview-of-public-health-and-social-measures-in-the-contextof-covid-19.

9. WHO. Critical preparedness, readiness and response actions for COVID-19: Interim guidance; 24 June 2020. https://www. who.int/publications/i/item/critical-preparedness-readinessand-response-actions-for-covid-19

10. Chilean Government (2020). COVID-19 Official Reports. https:// www.gob.cl/coronavirus/cifrasoficiales/

11. Cori A, Ferguson NM, Fraser C, Cauchemez S. A new framework and software to estimate time-varying reproduction numbers during epidemics. Am J Epidemiol. 2013;178(9):1505-12. https://doi. org/10.1093/aje/kwt133

12. Nishiura $H$, Linton NM, Akhmetzhanov AR. Serial interval of novel coronavirus (COVID-19) infections. Int J Infect Dis. 2020; 93: 284-6. doi: 10.1016/j.ijid.2020.02.060. https://www.ncbi.nlm.nih. gov/pubmed/32145466
13. Sanche S, Lin YT, Xu C, Romero-Severson E, Hengartner N, Ke R. High Contagiousness and Rapid Spread of Severe Acute Respiratory Syndrome Coronavirus 2. Emerg Infect Dis. 2020; https://doi. org/103201/eid2607.200282.

14. Lee VL, Chiew CJ, Khong WX. Interrupting transmission of COVID-19: lessons from containment efforts in Singapore. J Travel Med. 2020; https://doi.org/10.1093/jtm/taaa039

15. Russell T, Hellewell J, Abbott S, Golding N, Gibbs H, Jarvis $\mathrm{CI}$, et al. Using a delay-adjusted case fatality ratio to estimate under-reporting. CMMID; London School of Hygiene \& Tropical Medicine; 2020. CMMID Repository. https://cmmid.github.io/ topics/covid19/global_cfr_estimates.html.

16. Russell TW, Hellewell J, Jarvis CI, van Zandvoort K, Abbott S, Ratnayake R, et al. Estimating the infection and case fatality ratio for coronavirus disease (COVID-19) using age-adjusted data from the outbreak on the Diamond Princess cruise ship. Euro Surveill. 2020; doi: 10.2807/1560-7917.ES.2020.25.12.2000256.

17. Gonzalez RI, Muñoz F, Moya PS, Kiwi M. (2020). Is a COVID19 quarantine justified in Chile or USA right now? MedRxiv doi: https://doi.org/10.1101/2020.03.23.20042002.

18. SOCHIMI (2020). Encuesta diaria realidad nacional intensiva. Sociedad Chilena de Medicina Intensiva. https://www.medicinaintensiva.cl/site/post_covid.php?id=28\#gallery-1

19. Guan W, Ni Z, Hu Y, Liang W, Ou C, He J, et al. Clinical characteristics of Coronadisease. 2019 in China. N Engl J Med. 2020;382 (18):1708-20. https://www.nejm.org/doi/pdf/10.1056/NEJMoa20 02032?articleTools=true

20. WHO (2020). Report of the WHO-China Joint Mission on Coronavirus Disease 2019 (COVID-19) https://www.who.int/publications/ i/item/report-of-the-who-china-joint-mission-on-coronavirusdisease-2019-(covid-19).

21. Hur S, Kang J, Cho M, Lee S, Kang J. (2020). Current strategies for the control of COVID-19 in South Korea. DO. 10.5851/fl.2020.e1. https: / / www.researchgate.net/publication/340299228_Current_ strategies_for_the_control_of_COVID-19_in_South_Korea.

22. Lee VL, Chiew CJ, Khong WX. Interrupting transmission of COVID-19: lessons from containment efforts in Singapore. J Travel Med. 2020; https://doi.org/10.1093/jtm/taaa039

23. Anderson RM. Epidemiology. In: Modern parasitology (Cox FEG ed.). Blackwell Scientific Publications: Oxford; 1993. pp 75-117.

24. Fraser C, Riley S, Anderson RM, Ferguson NM. (2004). Factors that make an infectious disease controllable. Proc Natl Acad Sci USA. doi:10.1073/pnas.0307506101. https://www.pnas.org/content/101/ $16 / 6146$

25. Chowell G, Hyman JM, Bettencourt LMA, Castillo-Chavez C. Mathematical and statistical estimation approaches in epidemiology. Springer: Heidelberg; 2009.

26. Washio M, Oura A, Mori M. Ecological studies on influenza infection and the effect of vaccination: Their advantages and 
limitations. Vaccine. 2008;26(50):6470-72. https://doi.org/10.1016/j. vaccine.2008.06.037

27. Delamater PL, Street EJ, Leslie TF, Yang Y, Jacobsen KH. Complexity of the Basic Reproduction Number (R0). Emerg Infect Dis. 2019;25(1):1-4. https://dx.doi.org/10.3201/eid2501.171901.

28. Epiforecast and CMMID working group (2020). https://github. com/epiforecasts/covid.

29. Cuadrado C, Monsalves MJ, Gajardo J, Bertoglia MP, Najera M, Alfaro T, Canals M, Kaufmann J, Peña S. Impact of small-area lockdowns for the control of the COVID-19 pandemic. MedRxiv. 2020; https:/ / www.medrxiv.org/content/10.1101/2020.05.05.20092106v1

30. SOCHIMI (2020). Encuesta diaria realidad nacional intensiva. Sociedad Chilena de Medicina Intensiva. https://medicinaintensiva.cl/site/covid/img/noticias/informe_30JUN2020.pdf

31. Our World in Data (2020). Complete COVID-19 dataset. University of Oxford, Global Change Data Lab. https://github.com/owid/ covid-19-data/tree/master/public/data.
32. Du Z, Xu X, Wu Y, Wang L, Cowling BJ, Meyers LA. Serial interval of COVID-19 among publicy reported confirmed cases. Emerg Infect Dis. 2020; doi: 10.3201/eid2606.200357. https:/ / www.ncbi.nlm.nih. gov/pubmed /32191173

33. Li Q, Guan X, Wu P, Wang X, Zhou L, Tong Y., et al. Early Transmission Dynamics in Wuhan, China, of Novel CoronavirusInfected Pneumonia. NEJM. 2020; https://www.nejm.org/doi/ full/10.1056/NEJMoa2001316.

Manuscript submitted on 7 June 2020. Revised version accepted for publication on 9 July 2020 .

\section{Tendencia de la epidemia, respuesta de salud pública y capacidad del sistema de salud: la experiencia de Chile en cuatro meses de pandemia por COVID-19}

RESUMEN

Palabras clave
Objetivos. Informar sobre la vigilancia de la pandemia por COVID-19 en Chile, analizar la respuesta a las intervenciones de salud pública implementadas desde el 3 de marzo hasta el 30 de junio de 2020 y evaluar los riesgos de colapso del sistema de salud.

Métodos. Se analizó el número reproductivo efectivo, el subregistro de casos, la carga sobre las camas de cuidados intensivos disponibles, la tasa de letalidad y el número de pruebas diagnósticas de RT-PCR efectuadas para el SARS-CoV-2.

Resultados. Tras un inicio acelerado, la pandemia por COVID-19 parecía estar relativamente controlada en Chile a finales de abril de 2020, con números reproductivos cercanos a 1,00. Sin embargo, en ese momento, la carga de pacientes infectados activos era elevada, con un número importante de casos no notificados; la capacidad diagnóstica era todavía limitada y heterogénea entre las regiones del país. Desde el 1 de mayo hasta el 30 de junio se observó un marcado incremento exponencial en el número de casos, con un pico el 14 de junio. En este último período la ocupación de camas en las unidades de cuidados intensivos aumentó hasta el nivel de saturación (89\% a nivel nacional; 95\% en la Región Metropolitana).

Conclusiones. Nuestros hallazgos sugieren que las intervenciones de salud pública implementadas parecen haber sido efectivas inicialmente para disminuir la propagación de la pandemia. Las decisiones prematuras de relajar estas intervenciones pueden haber ocasionado un rebote en los casos con una rápida saturación del sistema de atención de salud.

Infecciones por coronavirus; pandemias; salud pública; política de salud; sistemas de salud; Chile. 